\title{
Obtuary/Necrólogo Necrólogo Janira Martins Costa (1941-2018)
}

\author{
Danielle Anjos-Santos $1 \bowtie$ \& Gisele Luziane de Almeida 2
}

1. Centro de Investigación Esquel de Montaña y Estepa Patagónica, CONICET-UNPSJB, Esquel, Argentina. 2. Faculdades São José, Rio de Janeiro, Brasil.

\section{EntomoBrasilis 11 (1): 63-64 (2018)}

$\int$ rofa. Dra. Janira Martins Costa (Figura 1), falecida em o8 de fevereiro de 2018 na cidade do Rio de Janeiro, aos 76 anos, foi uma entomologista brasileira que dedicou sua vida acadêmica a sistemática e taxonomia das libélulas, insetos da Ordem Odonata.

Pernambucana de Olinda, nascida em o5 de dezembro de 1941, Janira Martins Costa era filha do militar Francisco de Souza Martins e da professora Ana Rosa Pedreira Martins. Mudou-se anos depois para a cidade do Rio de Janeiro, onde cursou Bacharelado e Licenciatura em História Natural na Universidade Gama Filho, onde graduou-se em 1967. Iniciou sua vida acadêmica em 1964 como estagiária do Museu Nacional da Universidade Federal do Rio de Janeiro (MN/UFRJ), sob a orientação do Dr. Newton Dias dos Santos, entomólogo e educador, considerado o pai da Odonatologia Brasileira.

Janira Costa foi docente em diversas instituições: Universidade Federal de Santa Maria, UFSM (1968-1969); Centro de Aperfeiçoamento de Ciências da Guanabara, CECIGUA (19701972); Faculdade de Humanidades Pedro II, FAHUPE (19701979); Universidade Gama Filho, UGF (1970-1991); Universidade Federal Rural do Rio de Janeiro, UFRRJ (1972-1976).

Em 1976 foi aprovada em concurso pela UFRJ como Professora Assistente de Zoologia do Museu Nacional e a esta Instituição dedicou-se com intensidade e entusiasmo, desempenhando diversas atividades de ensino, pesquisa e extensão.

Pela UFRJ, obteve o título de Mestre em Ciências Biológicas (Zoologia) em 1977 e Doutorado e Livre-Docência em 1985.

De 1994 a 1998 foi diretora do Museu Nacional, sendo destaques de sua gestão: o primeiro convênio firmado entre o Museu Nacional, a Petrobras, o Ministério de Cultura e o Instituto Herbert Levy para início de obras de restauração do Museu; a implementação do Curso de Doutorado em Ciências Biológicas (Zoologia) e aquisição da coleção científica do Dr. José Cândido de Mello Carvalho, composta por cerca de 20.000 exemplares.

Foi coordenadora do Programa de Pós-graduação em Zoologia em Ciências -Biológicas Zoologia (PPGZoo) por dois períodos (1989-1994; 2004-2006) e chefe do Departamento de Entomologia em diversas ocasiões.

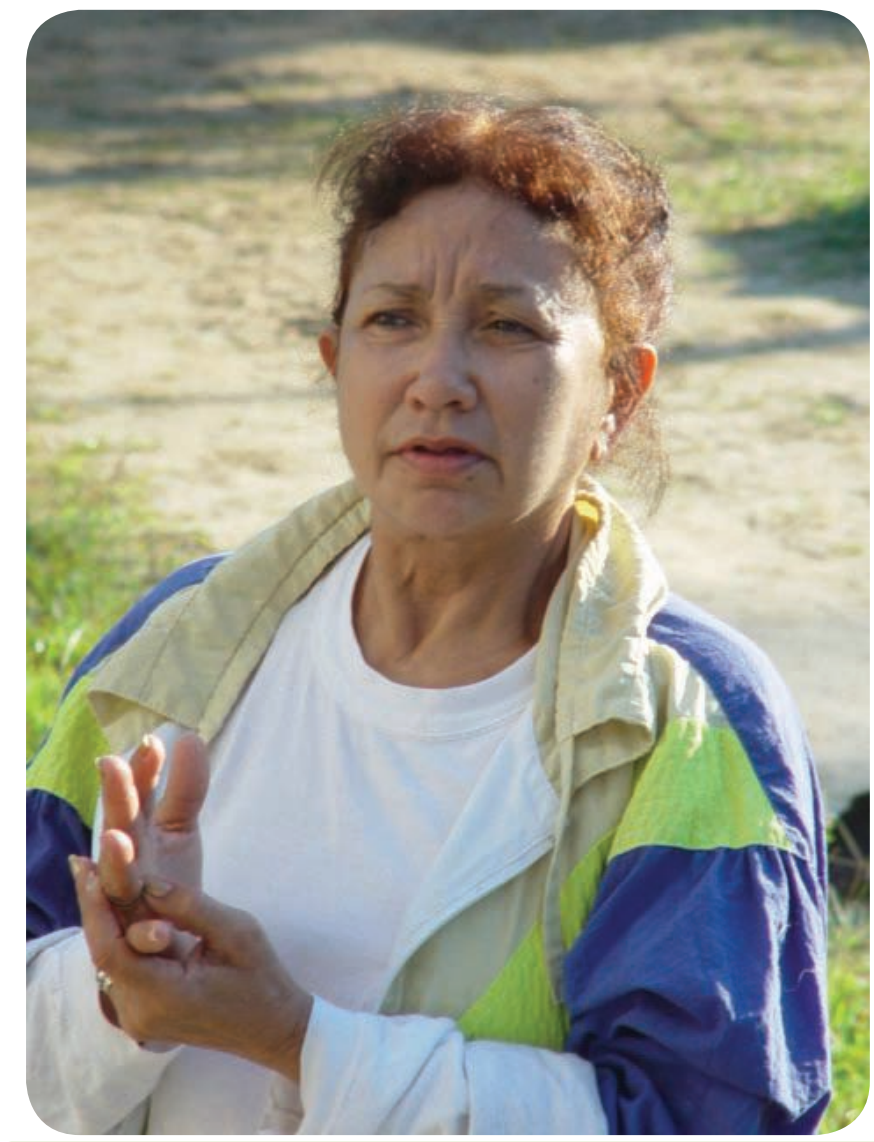

Figura 1. Professora Dra. Janira Martins Costa na disciplina Zoologia de Campo da UFRRJ, na Ilha da Marambaia em julho de 2005.

A vida Acadêmica de Janira Costa refletiu seu grande entusiasmo pela taxonomia dos Odonata, mesmo em períodos de férias costumava dedicar algumas horas a pesquisa no laboratório de Insetos Aquáticos do Museu Nacional. Realizou diversas expedições científicas por estados do Sudeste, Centro-Oeste e Norte do país, assim como, por países da América Latina como Paraguai, Uruguai e Argentina, incrementando a Coleção de Odonata do Museu Nacional, da qual foi curadora até 2012. Recebeu a inúmeros pesquisadores brasileiros e estrangeiros, formando redes de pesquisas colaborativas com estes

\section{Edited by:}

William Costa Rodrigues

\section{Article History:}

Received: 04.iv.2018

Accepted: 16.iv.2018

\section{Corresponding author:}

Danielle Anjos-Santos

\} danielleanjos2@yahoo.com.br

(3) http://orcid.org/0000-0002-2889-5964

\section{Funding agencies:}

$\checkmark$ Without funding declared 
profissionais. Também reorganizou a Coleção de Odonata do Instituto Nacional de Pesquisas Amazônicas (INPA).

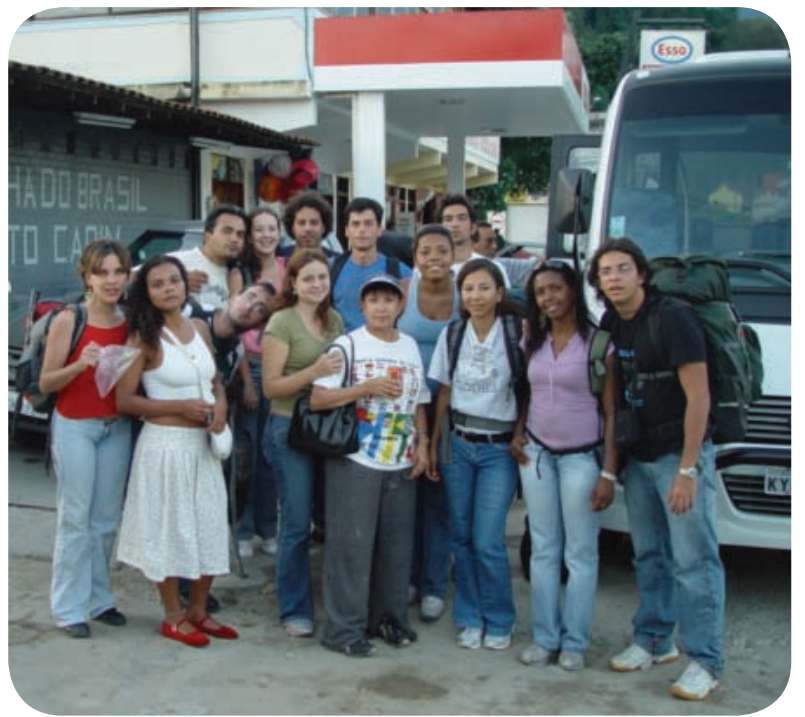

Figura 2. Professora Janira Martins Costa em julho de 2005, com alunos de Pós-graduação da UFRRJ e Museu Nacional/UFRJ e estagiários do Laboratório de Insetos Aquáticos do Museu Nacional no Porto de Itacuruçá/Magaratiba, a caminho da Ilha da Marambaia.

Foi orientadora de inúmeros estudantes desde a iniciação científica até o doutorado, alguns destes profissionais hoje são professores, pesquisadores ou técnicos em Instituições Brasileiras e Argentinas. Orientou dissertações, teses e ministrou aulas em programas de Pós-graduação na UFRJ, na UFRRJ, na Universidade Federal do Mato Grosso do Sul (UFMS) e na Universidade Federal da Grande Dourados (UFGD) (Figura 2), bem como supervisionou pós-doutorandos brasileiros e estrangeiros.

Participou de vários Eventos científicos Nacionais (Figura 3) e Internacionais e contribuiu para o conhecimento do grupo publicando 96 artigos científicos, 1 livro e 11 capítulos de livro sobre os Odonata neotropicais, em especial sobre a fauna brasileira. Realizou assessorias, consultorias etrabalhos técnicos, além de participar de entrevista televisivas e de mídia impressa, difundindo informações e curiosidades sobre as libélulas. Foi membro da Sociedade Brasileira de Entomologia, da Sociedade Entomológica do Brasil, da Revista Brasileira de Zoologia, da Revista Odonatologica (International Odonatological Foundation, Societas Internationalis Odonatologica) e da Revista International Journal of Odonatology. Foi consultora científica do INPA, da Universidade Federal da Bahia e consultora ad hoc de vários periódicos nacionais e internacionais como: Iheringea - Série Zoologia, Neotropical Entomology, Institute of Ecology
State University of Ghent (Bélgica), National Geografic Society e de agências de fomento.

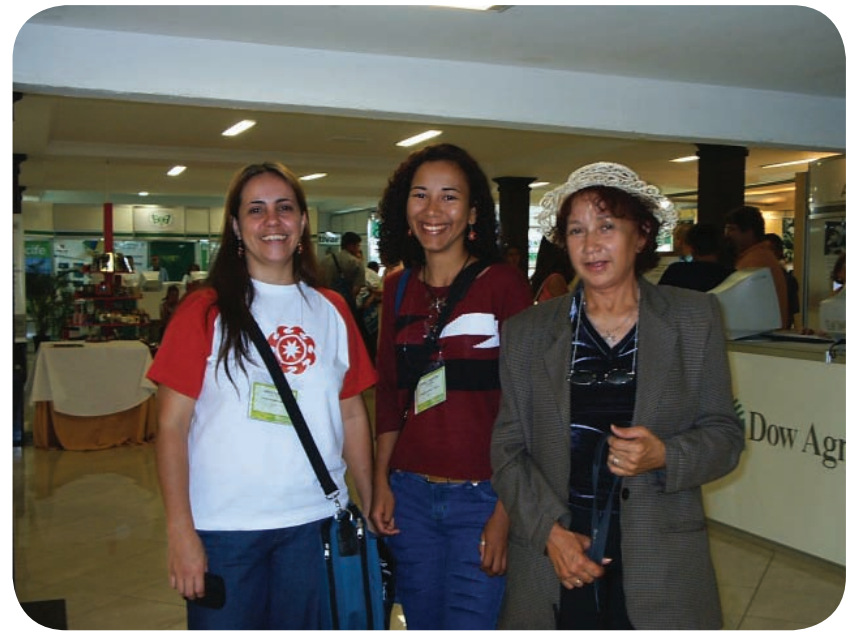

Figura 3. Integrantes do Laboratório de Insetos Aquáticos do Museu Nacional/UFRJ no XXCBE, Gramado 2004. Da esquerda para a direita: Profa. Dra. Gisele Luziane de Almeida, Profa. Dra. Danielle Anjos dos Santos, Profa. Dra. Janira Martins Costa.

Em 1997 foi premiada com uma placa de prata pela presidência do XV Congreso Venezolano de Entomología, Universidad Nacional de Trujillo, Venezuela e em 2006 recebeu Monção da Câmara Municipal do Rio de Janeiro. Além disso, teve seu profissionalismo como docente reconhecido por vários alunos do curso de Ciências Biológicas da Universidade Gama Filho, que a convidaram para ser Paraninfo e Patrono em diversas turmas de formandos.

Em 2012, já como Professora Titular do Museu Nacional/UFRJ, se aposentou compulsoriamente. Continuou frequentando o laboratório de forma esporádica, deixando aos poucos este vínculo tão forte com uma Instituição que foi seu lar, sua família e sua vida.

\section{REFERÊNCIAS}

Currículo Lattes, 2018. Janira Martins Costa. Última atualização do Currículo em 08.04.2014. Disponível em: $<$ http://lattes.cnpq.br/0848325826429562>. Acesso em: 08.03.2018.

Seção de Museologia, 2007/2008. Os Diretores do Museu Nacional/UFRJ. Disponível em: <http://www. museunacional.ufrj.br/site/assets/pdf/memoria 1.pdf $>$. Acesso em: 08.03.2018.

$$
* * * * * * * * * *
$$

\section{Suggestion citation:}

Anjos-Santos, D. \& G.L. Almeida, 2018. Necrólogo Janira Martins Costa (1941-2018). EntomoBrasilis, 11 (1): 63-64. Available on: doi:10.12741/ebrasilis.v11i1.781
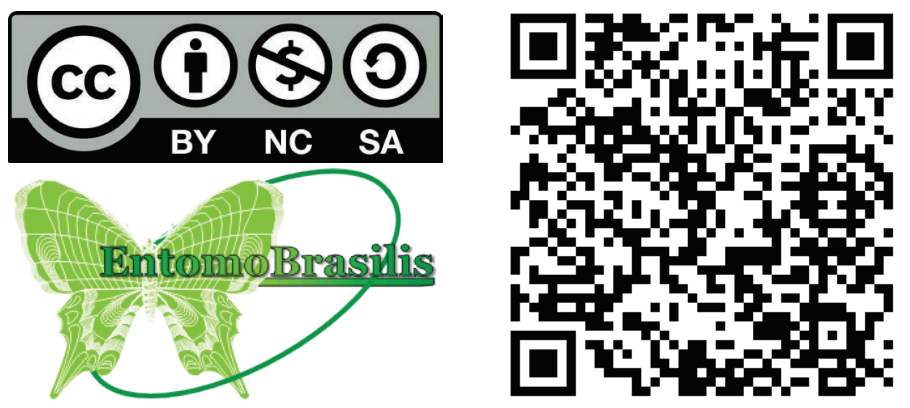